\title{
Solar Integrated Anaerobic Digester: Energy Savings and Economics
}

\author{
Lidia Lombardi ${ }^{1, *}\left(\mathbb{D}\right.$, Barbara Mendecka $^{2}$ and Simone Fabrizi ${ }^{1}$ \\ 1 Department of Engineering, Niccolò Cusano University, 00166 Rome, Italy; simone.fabrizi@unicusano.it \\ 2 Department of Economics, Engineering, Society and Business Organization, University of Tuscia, \\ 01100 Viterbo, Italy; barbara.mendecka@unitus.it \\ * Correspondence: lidia.lombardi@unicusano.it
}

Received: 23 July 2020; Accepted: 14 August 2020; Published: 19 August 2020

\begin{abstract}
Industrial anaerobic digestion requires low temperature thermal energy to heat the feedstock and maintain temperature conditions inside the reactor. In some cases, the thermal requirements are satisfied by burning part of the produced biogas in devoted boilers. However, part of the biogas can be saved by integrating thermal solar energy into the anaerobic digestion plant. We study the possibility of integrating solar thermal energy in biowaste mesophilic/thermophilic anaerobic digestion, with the aim of reducing the amount of biogas burnt for internal heating and increasing the amount of biogas, further upgraded to biomethane and injected into the natural gas grid. With respect to previously available studies that evaluated the possibility of integrating solar thermal energy in anaerobic digestion, we introduce the topic of economic sustainability by performing a preliminary and simplified economic analysis of the solar system, based only on the additional costs/revenues. The case of Italian economic incentives for biomethane injection into the natural gas grid-that are particularly favourable - is considered as reference case. The amount of saved biogas/biomethane, on an annual basis, is about $4-55 \%$ of the heat required by the gas boiler in the base case, without solar integration, depending on the different considered variables (mesophilic/thermophilic, solar field area, storage time, latitude, type of collector). Results of the economic analysis show that the economic sustainability can be reached only for some of the analysed conditions, using the less expensive collector, even if its efficiency allows lower biomethane savings. Future reduction of solar collector costs might improve the economic feasibility. However, when the payback time is calculated, excluding the Italian incentives and considering selling the biomethane at the natural gas price, its value is always higher than 10 years. Therefore, incentives mechanism is of great importance to support the economic sustainability of solar integration in biowaste anaerobic digestion producing biomethane.
\end{abstract}

Keywords: anaerobic digestion; biogas; biomethane; integration; solar thermal energy

\section{Introduction}

Biogas is a renewable fuel produced by the anaerobic digestion (AD) of biodegradable organic substrates and its main components are $\mathrm{CH}_{4}$ and $\mathrm{CO}_{2}$. The main sources of biogas are municipal solid waste landfills, digesters of sludge from wastewater treatment plants and industrial anaerobic digestion plants using different feedstocks as biowaste, manure, and energy crops. With reference to 2017, the production of biogas as primary energy in the European Union (EU) was about 16,811,000.6 ton of oil equivalent (toe), mainly generated by $\mathrm{AD}$ processes of different substrates (excluding sewage sludge). The main biogas producers were Germany (46.7\%), United Kingdom (16.2\%), and Italy (11.3\%) [1].

Biogas can be directly used in gas turbines, internal reciprocating combustion engines, fuel cells, or organic Rankine Cycles [2]. However, the possibility of upgrading biogas to biomethane, i.e., namely 
by $\mathrm{CO}_{2}$ removal, used for fuelling vehicles or for injection into the natural gas grid, is already quite frequent in Northern Europe and it is gaining increasing interest worldwide. Biomethane, being renewable, can replace natural gas: its expected future increased production and use can provide an important contribution in decreasing the heavy dependency on foreign supply of several EU countries. To this aim, several EU countries developed devoted types of subsidy systems, to boost the biomethane production and use: a summary of incentive scheme is reported in Lombardi and Francini [3]. Around 540 biogas plants with biomethane upgrading were active in Europe in 2017 [4]. In Italy, there were about 7 plants producing biomethane in 2018 [5], thanks also to the latest economic incentives promoting the production of biomethane to be injected into the natural gas grid and used for transportation purposes.

Industrial AD requires thermal energy to heat the feedstock and maintain mesophilic or thermophilic process conditions inside the reactor (compensating for heat loss to the environment). It is quite common that the required thermal energy can be recovered from the exhausts of the internal combustion engine fuelled by biogas. However, in some cases the thermal requirements are satisfied by burning part of the biogas in devoted boilers.

Some authors proposed to provide the AD required thermal energy by solar integration, with different purposes for various specific applications.

Mahmudul and Rasul [6], in their study regarding opportunities for solar assisted biogas plant in subtropical climate in Australia, assessed the possible benefits and challenges of the process, highlighting that it may reach higher biogas yield by increasing digester temperature and hence improved possibilities for recovering energy from waste. Another study, on small fermentation system [7] integrated with solar collectors, showed that at Hothot (China) in October, an area of $2 \mathrm{~m}^{2}$ of solar collectors, running $8 \mathrm{~h}$, can provide the heat required by $6 \mathrm{~m}^{3}$ digester.

Ouhammou et al. [8] studied an up-flow anaerobic sludge blanket (UASB) digester coupled with solar thermal system, located in western North Morocco, and concluded that it allows saving $100 \%$ of energy consumption for almost ten months per year and $70 \%$ for two cold months per year.

The coupling of anaerobic digestion and solar thermal energy can be viewed also as way to store the solar energy into biogas, as proposed by Zhong et al. [9] for the case of mesophilic digestion and co-digestion of manure, who concluded that the preferred system to store solar energy into methane biogas is the mesophilic case.

Borrello et al. [10] proposed to integrate a solar collector system, equipped with thermal storage, into a mesophilic anaerobic digester with the aim of continuously providing the required thermal power. Specifically, the considered digester is a wet continuous flow stirred tank reactor (CSTR) with a volume of $320 \mathrm{~m}^{3}$, fed by an organic load of $5 \mathrm{kgVS} / \mathrm{m}^{3} \mathrm{~d}$. They concluded that digester needs a solar field equal to $560 \mathrm{~m}^{2}$.

Thus, using solar energy as heat source for the $\mathrm{AD}$ is an interesting solution for maintaining the required temperature inside the reactor. Especially in the $\mathrm{AD}$ plants where biogas is upgraded to biomethane, where biogas boilers are generally used, the possibility of avoiding or at least reducing the biogas self-consumption is directly translated into higher amount of biomethane for being injected into the grid, and this can represent a significant increased revenue, especially when incentives for biomethane injection are acknowledged.

However, the economic evaluations of solar thermal energy integration into AD reactors was not investigated in the previously mentioned studies. Thus, the present work aims to contribute at filling this gap, introducing a preliminary economic analysis.

In particular, this study aims to investigate the possibility to integrate thermal solar collectors into a mesophilic or thermophilic biowaste anaerobic digestion plant, equipped with the upgrading section producing biomethane. The amount of thermal energy that can be supplied yearly by the solar source, using different collector types and for different geographical locations, is evaluated. The supplied solar thermal energy allows saving part of the biogas-generally used for heating the reactor-that can be additionally upgraded to biomethane. The amount of yearly saved biomethane is presented and a 
preliminary economic evaluation of the additional costs and additional revenues, with respect to the reference case (mesophilic/thermophilic anaerobic digestion without solar integration), is reported in term of payback time of the additional investment.

\section{Materials and Methods}

\subsection{System Description}

The studied concept refers to the AD reactor integrated with solar collector system. Figure 1 shows the layout of the investigated system. Two operating conditions of the anaerobic reactor are studied, in particular the mesophilic and thermophilic conditions. AD plant is fed by about $9.800 \mathrm{t} / \mathrm{y}$ of source-sorted organic fraction of municipal solid waste (SS-OFMSW), with 70\% moisture content for both operating conditions. Different digester types can be used for the AD of organic wastes. The selected type depends on operational factors, including the nature of the waste to be treated, e.g., its solid content [11]. In this study the reactor is assumed to be a conventional wet one, based on the CSTR model, working with total solids (TS) content equal to $12 \%$, 365 days per year. Assuming for the SS-OFMSW a density equal to $1.12 \mathrm{t} / \mathrm{m}^{3}$, the flow rate entering the reactor resulted $157 \mathrm{t} /$ day (12\% TS), equal to $140 \mathrm{~m}^{3} /$ day. The expected biogas production rate for the mesophilic and thermophilic conditions are $140 \mathrm{Nm}^{3} / \mathrm{h}$ and $168 \mathrm{Nm}^{3} / \mathrm{h}$, respectively, with $60 \%$ volumetric content of $\mathrm{CH}_{4}$. The typical hydraulic retention time (HRT) is 15 and 21 days in thermophilic and mesophilic condition, respectively. A summary of the working parameters of the anaerobic digester for both conditions is presented in Table 1.

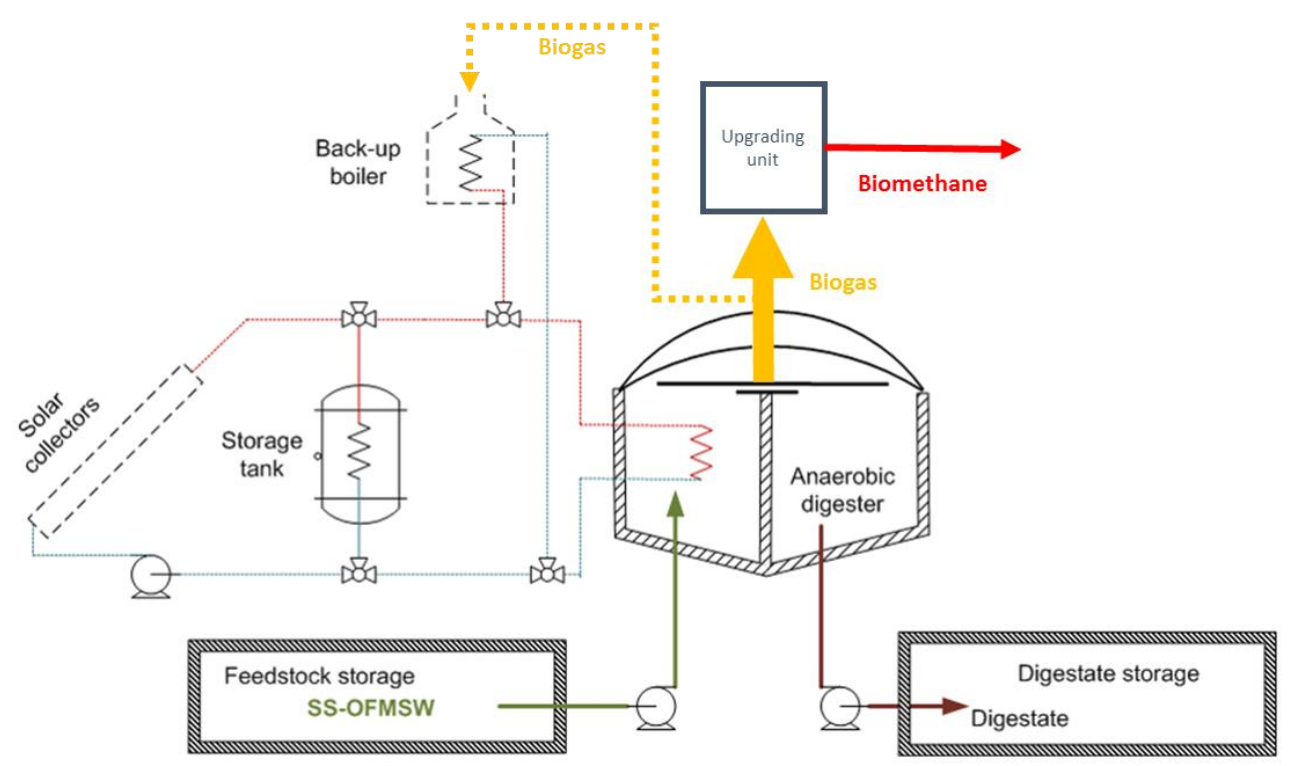

Figure 1. Schematic layout of the solar-integrated anaerobic digester.

Table 1. Operating conditions of the anaerobic digesters.

\begin{tabular}{cccc}
\hline \multirow{2}{*}{ Parameter } & Description & \multicolumn{2}{c}{ Conditions } \\
\cline { 3 - 4 } & & Mesophilic & Thermophilic \\
\hline $\mathrm{T}$ & Temperature $\left({ }^{\circ} \mathrm{C}\right)$ & 37 & 55 \\
$\mathrm{HRT}$ & Hydraulic retention time $($ days $)$ & 21 & 15 \\
$\mathrm{Q}_{\text {biogas }}$ & Biogas production $\left(\mathrm{Nm}^{3} / \mathrm{h}\right)$ & 140 & 168 \\
$\mathrm{Q}_{\mathrm{CH}}$ & Biomethane production $\left(\mathrm{Nm}^{3} / \mathrm{h}\right)$ & 84 & 100.8 \\
\hline
\end{tabular}

The reactor is assumed to be built in reinforced concrete material, with cylindrical shape and flat cover. Its volume is calculated from the inlet volumetric flow rate and the HRT, considering an extra 
volume of about $17.5 \%$. Technical and geometric data of the reactor, for both operating conditions, are presented in Table 2.

Table 2. Characteristics of the anaerobic digesters.

\begin{tabular}{cccc}
\hline \multirow{2}{*}{ Parameter } & Description & \multicolumn{2}{c}{ Conditions } \\
\cline { 3 - 4 } & & Mesophilic & Thermophilic \\
\hline $\mathrm{H}_{1}$ & Height from ground to substrate $(\mathrm{m})$ & 9 & - \\
$\mathrm{H}_{2}$ & Height for biogas filling $(\mathrm{m})$ & 2 & - \\
$\mathrm{H}_{\text {buried }}$ & Buried height of the digester $(\mathrm{m})$ & 20 & - \\
$\mathrm{D}$ & Diameter of the anaerobic digester $(\mathrm{m})$ & 3454 & 2467 \\
$\mathrm{~V}$ & Volume of the anaerobic digester $\left(\mathrm{m}^{3}\right)$ & & 0.2 \\
$\mathrm{~d}_{1}$ & Thickness of reinforced concrete walls $(\mathrm{m})$ & & 0.15 \\
$\mathrm{~d}_{2}$ & Thickness of the insulation $(\mathrm{m})$ & 0.15 \\
$\mathrm{~d}_{3}$ & Thickness of the cover $(\mathrm{m})$ & & \\
\hline
\end{tabular}

Several biogas upgrading technologies are available on the market, each one with specific advantages and drawbacks. However, they are quite similar in terms of consumptions and yields [3], being the high-pressure water scrubbing (HPWS) the most popular on a commercial basis [12]. The expected biomethane output flows, for the mesophilic and thermophilic conditions, are $84.00 \mathrm{Nm}^{3} / \mathrm{h}$ and $100.80 \mathrm{Nm}^{3} / \mathrm{h}$, respectively.

The thermal system providing heat to the reactor consists of a solar collector field, storage tank, and biogas back-up boiler. Different collector types are investigated to produce hot water which feds the reactor-heating loop. The collector types utilized in this study are depicted in Figure 2. Three plane collector designs are selected for performance and economic comparison analysis: flat plate collector-glazed FKC-2W by Bosch [13]; flat plate collector FT 226-2V by Bosch [13]; evacuated tubular collector VTK 120-2 CPC by Bosch [13]. Bosch FKC-2W flat solar collector is composed by the pre-moulded tank and aluminium pick-up plate, absorber with a selective inox finish [13]. FT 226-2V solar collector has a copper and aluminium absorber with PVD coating and a double-twisted geometry of the hydraulic circuit [8]. The third solar collector is the Bosch VTK 120-2 CPC: it has very high performance guaranteed throughout the year thanks to evacuated technology, where the pipes inside the collector are kept under vacuum [13]. Technical data of the chosen collectors are presented in Table 3.

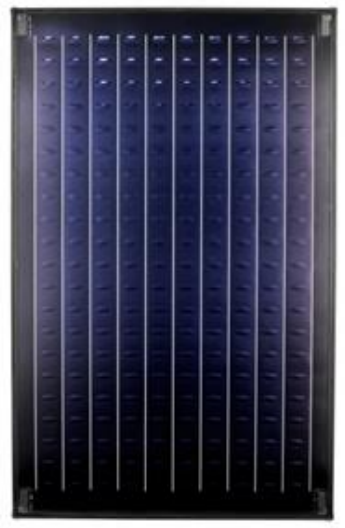

(a)

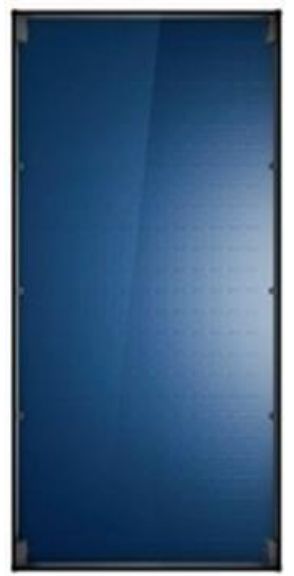

(b)

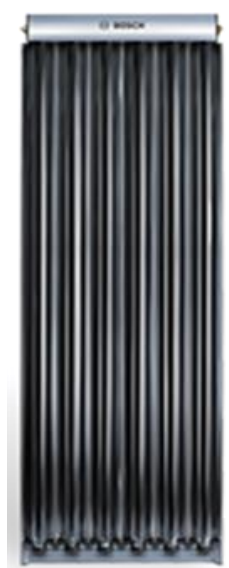

(c)

Figure 2. Type of considered collectors: (a) FKC-2W; (b) FT 226-2V; (c) VTK 120-2 CPC. 
Table 3. Technical data of the three types of collectors.

\begin{tabular}{ccccc}
\hline \multirow{2}{*}{ Parameter } & Description & FKC-2W & FT & VTK 120-2 \\
& & 226-2V & CPC \\
\hline$\eta_{0}$ & Zero loss collector efficiency $(\%)$ & 77.00 & 79.40 & 66.30 \\
$\mathrm{~b}$ & Slope of surface & $45^{\circ}$ & $45^{\circ}$ & $45^{\circ}$ \\
$\mathrm{a}_{1}$ & Linear heat loss coefficient $\left(\mathrm{W} / \mathrm{m}^{2} \mathrm{~K}\right)$ & 3.87 & 3.86 & 0.782 \\
$\mathrm{a}_{2}$ & Quadratic heat loss coefficient $\left(\mathrm{W} / \mathrm{m}^{2} \mathrm{~K}^{2}\right)$ & 0.012 & 0.013 & 0.012 \\
$\mathrm{IAM}_{\text {tra }}$ & Transversal incidence angle modifier $\left(\theta=50^{\circ}\right)$ & 0.92 & 0.94 & 1.09 \\
$\mathrm{IAM}_{\text {lon }}$ & Longitudinal incidence angle modifier $\left(\theta=50^{\circ}\right)$ & & & 0.95 \\
$\mathrm{~A}$ & Aperture of the collector $\left(\mathrm{m}^{2}\right)$ & 2.25 & 2.55 & 1.22 \\
\hline
\end{tabular}

Incidence angle modifier (IAM) is a function of declination, local hour angle, latitude, longitude, and solar azimuth angle obtained from the solar radiation and weather data processor in TRNSYS software (TRNSYS 18, Solar Energy Laboratory, University of Wisconsin, Madison, WI, USA). The IAM is provided by the manufacturer, as a set of IAM factors associated with given incidence angles. The value of IAM, for the simulation purpose, can be obtained by interpolation based on data reported in Table 4.

Table 4. Prediction of incidence angle modifier value according to manufacturer data [14-16].

\begin{tabular}{|c|c|c|c|c|c|c|c|}
\hline $\begin{array}{c}\text { Incidence Angle } \\
\theta^{\circ}\end{array}$ & 10 & 20 & 30 & 40 & 50 & 60 & 70 \\
\hline \multicolumn{8}{|c|}{ FKC-2W } \\
\hline IAM $_{\text {tra }}$ & 1.00 & 0.99 & $\begin{array}{l}0.98 \\
226-2 \mathrm{~V}\end{array}$ & 0.96 & 0.92 & 0.86 & 0.73 \\
\hline IAM $_{\text {tra }}$ & 1.00 & 0.99 & 0.98 & 0.97 & 0.94 & 0.90 & 0.80 \\
\hline \multicolumn{8}{|c|}{ VTK 120-2 CPC } \\
\hline $\mathrm{IAM}_{\text {tra }}$ & 1.01 & 1.00 & 0.96 & 1.03 & 1.09 & 1.18 & 1.36 \\
\hline $\mathrm{IAM}_{\mathrm{lon}}$ & 1.00 & 0.99 & 0.99 & 0.97 & 0.95 & 0.91 & 0.83 \\
\hline
\end{tabular}

The solar system is coupled with the water thermal storage, assumed to be a shell and tube arrangement, with water as the heat transfer fluid and also circulating in the inside tube.

However, when the solar radiation is not enough, the reactor heat duty is supplied by a backup biogas-fired boiler, operating in parallel with the thermal storage. Biogas and solar energy can be used in combination or independently, depending on irradiation conditions and on the reactor requests.

The aim is to keep the reactor temperature at the desired level $37^{\circ} \mathrm{C}$ in the mesophilic condition and $55{ }^{\circ} \mathrm{C}$ in the thermophilic condition-minimising auxiliary biogas consumption. The preferred energy source is, of course, the solar radiation, but, since it cannot be altered, the control system keeps the desired inlet temperature conditions, by handling the biogas boiler. It is assumed that the biogas boiler back-up system operates only when the storage tank level is lower than $10 \%$, and there is no (or not enough) energy from the solar collector field available at the given moment.

\subsection{Thermal Modelling}

The simulation is performed for each hour of one year, calculating heat losses and gains, assuming the weather conditions for three reference sites in Italy. Milano (site 1), Frosinone (site 2), and Enna (site 3) are considered as reference sites, for which the hourly meteorological data (external temperature, wind speed, direct normal irradiance, global irradiance, and incidence angle) are collected. The three sites are representative of the variation of global solar radiation $(G)$ through the Italian territory. Figure 3 shows that the first site (site 1) falls in an area with low global irradiation of about $1300 \mathrm{kWh} / \mathrm{m}^{2}$ as yearly totals, while for the second (site 2) and third site (site 3) the global irradiation values are about 1600 and $1900 \mathrm{kWh} / \mathrm{m}^{2}$ as yearly totals, respectively. The average values of meteorological data for the reference sites are given in Table 5 . 


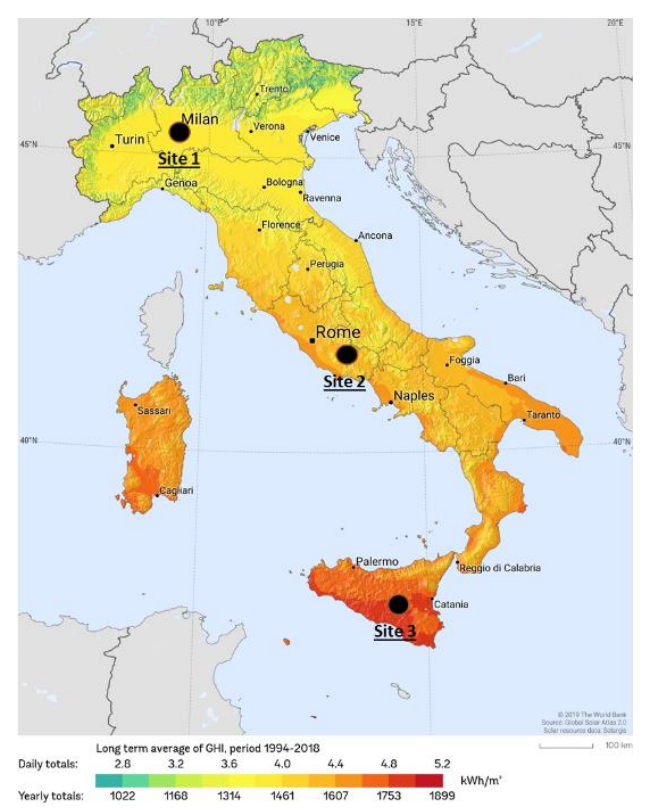

Figure 3. Global Irradiation map. Reproduced from [17], Global Solar Atlas: 2019.

Table 5. Geographical position and average meteorological parameters for the three considered sites.

\begin{tabular}{cccc}
\hline Parameter & Site 1 & Site 2 & Site 3 \\
\hline Longitude & $9^{\circ} 13^{\prime} \mathrm{E}$ & $13^{\circ} 19^{\prime} 12^{\prime \prime} \mathrm{E}$ & $14^{\circ} 10^{\prime} 34^{\prime \prime} \mathrm{E}$ \\
Latitude & $45^{\circ} 28^{\prime} \mathrm{N}$ & $41^{\circ} 38^{\prime} 24^{\prime \prime} \mathrm{N}$ & $37^{\circ} 31^{\prime} 03^{\prime \prime} \mathrm{N}$ \\
Average annual temperature & $14.29^{\circ} \mathrm{C}$ & $15.33^{\circ} \mathrm{C}$ & $15.90^{\circ} \mathrm{C}$ \\
Average annual wind sped (Ws) & $1.69 \mathrm{~m} / \mathrm{s}$ & $1.05 \mathrm{~m} / \mathrm{s}$ & $1.38 \mathrm{~m} / \mathrm{s}$ \\
Average annual direct normal irradiance (DNI) & $182.36 \mathrm{~W} / \mathrm{m}^{2}$ & $191.56 \mathrm{~W} / \mathrm{m}^{2}$ & $211.40 \mathrm{~W} / \mathrm{m}^{2}$ \\
Average annual global irradiance (G) & $290.88 \mathrm{~W} / \mathrm{m}^{2}$ & $315.30 \mathrm{~W} / \mathrm{m}^{2}$ & $409.90 \mathrm{~W} / \mathrm{m}^{2}$ \\
\hline
\end{tabular}

The simulation of the system resolves the energy balances, on hourly basis using two software (TRNSYS 18 and Matlab R2018b (R2018b, MathWorks, Natick, MA, USA)). Random availability of the solar source is assumed in the model, being a very important feature when dealing with renewable sources [18]. As results, hourly load profiles of the reactor are obtained for each site under study and the two operating conditions of the anaerobic digester system.

Thermal load of the reactor $\mathrm{Q}_{\mathrm{AD} \text {.load }}$ is the sum of the thermal energy to heat the substrate to the required temperature $Q_{\text {sub }}$ and the thermal energy required to compensate heat losses through the external walls of the reactor to environment $Q_{\text {disp }}(1)$ :

$$
\mathrm{Q}_{\mathrm{AD} . \mathrm{load}}=\mathrm{Q}_{\mathrm{sub}}+\mathrm{Q}_{\text {disp }}
$$

Thermal energy lost from the reactor walls to the surroundings by conduction, convection, and radiation is represented as the product of heat transfer coefficient $U_{i}$, wall area $A_{i}$ and the temperature difference between the reactor internal temperature $\mathrm{T}_{\text {dig }}$ and the ambient temperature $\mathrm{T}_{\mathrm{Db}}(2)$.

$$
\mathrm{Q}_{\text {disp }}=\mathrm{U}_{\mathrm{i}} \cdot \mathrm{A}_{\mathrm{i}} \cdot\left(\mathrm{T}_{\mathrm{dig}}-\mathrm{T}_{\mathrm{Db}}\right)
$$

where the heat transfer coefficient is given by (3):

$$
\mathrm{U}_{\mathrm{i}}=\frac{1}{\left(\frac{1}{\alpha_{1 . \mathrm{sub}}}\right)+\sum \frac{\mathrm{d}}{\mathrm{k}}+\left(\frac{1}{\alpha_{1 . \mathrm{amb}}}\right)}
$$


and $\alpha_{1 . a m b}$ is the external heat transfer coefficient; it is a function of the wind speed Ws in $\mathrm{m} / \mathrm{s}$, it depends on the external conditions [19] and it is given by (4):

$$
\alpha_{1 . \mathrm{amb}}=4+4 \cdot \mathrm{Ws}
$$

Conductive and internal convective heat transfer coefficients and heat exchange areas used in the calculations are presented in Table S1 in the Supplementary Materials.

$\mathrm{T}_{\text {dig }}$ is the temperature of the digester $37^{\circ} \mathrm{C}$ or $55^{\circ} \mathrm{C}$, while $\mathrm{T}_{\mathrm{Db}}$ is the dry-bulb temperature supplied by the meteorological stations for each hour of the year.

$\mathrm{Q}_{\text {sub }}$ is given by (5):

$$
\mathrm{Q}_{\mathrm{sub}}=\dot{\mathrm{m}} \cdot \mathrm{c}_{\mathrm{p}} \cdot \Delta \mathrm{t}
$$

where $\dot{m}$ is the mass flow of the entering substrate, equal to $157 \mathrm{t} /$ day; $c_{\mathrm{p}}$ is the specific thermal capacity of the substrate equal to $4186 \mathrm{~J} / \mathrm{kg} \mathrm{K} ; \Delta \mathrm{t}$ is the temperature difference between the initial and final temperature of the substrate entering the reactor.

Table 6 shows gross annual amount as energy content of biogas produced annually by the anaerobic digester, the annual consumption of biogas, without solar collectors, fed to the boiler for heating the digester, and the annual amount of biogas converted to biomethane (cases without solar integration).

Table 6. Annual amount of biogas produced, required by the boiler and available for biomethane production, at the three considered sites, for mesophilic and thermophilic conditions, without solar

\begin{tabular}{|c|c|c|}
\hline \multirow{2}{*}{ Description } & \multicolumn{2}{|c|}{ Conditions } \\
\hline & Mesophilic & Thermophilic \\
\hline Biogas produced by AD (MWh/year) & 7154 & 8585 \\
\hline \multicolumn{3}{|c|}{ site 1} \\
\hline Biogas required by the boiler (MWh/year) & 1492 & 2729 \\
\hline Biogas to biomethane (MWh/year) & 5662 & 5856 \\
\hline \multicolumn{3}{|c|}{ site 2} \\
\hline Biogas required by the boiler (MWh/year) & 1476 & 2713 \\
\hline Biogas to biomethane (MWh/year) & 5678 & 5871 \\
\hline \multicolumn{3}{|c|}{ site 3} \\
\hline Biogas required by the boiler (MWh/year) & 1424 & 2662 \\
\hline Biogas to biomethane (MWh/year) & 5730 & 5923 \\
\hline
\end{tabular}
system integration.

It is noted that even in the thermophilic case, the heat duty is higher, also the biogas sent to biomethane production is higher because of the higher specific production. In general, in the thermophilic case without solar systems, about 3.3\% more biogas is available for upgrading than in the mesophilic case.

\subsection{Solar System Design}

A parametric analysis is performed varying both solar collectors field area and thermal storage size in order to compare the energy gain and the economic feasibility of the proposed solutions. The area of the solar collector field is calculated for the maximum thermal power demand of the reactor $\mathrm{Q}_{\mathrm{AD} \text {.load.max }}$ and varying design solar irradiation $\mathrm{DNI}_{\text {design }}$ from 100 to $800 \mathrm{~W} / \mathrm{m}^{2}$ with a step of $25 \mathrm{~W} / \mathrm{m}^{2}(6)$.

$$
\mathrm{A}=\frac{\mathrm{Q}_{\mathrm{AD} \cdot \text { load.max }}}{\mathrm{DNI}_{\mathrm{design}} \cdot \eta_{\mathrm{th}} \cdot \mathrm{X}}
$$


where:

- $\mathrm{X}$ is the collector cleanliness factor, minimization criterion, it is equal to 1 in the low range temperature $\left(50-100{ }^{\circ} \mathrm{C}\right)[20]$;

- $\quad \eta_{\text {th }}$ is the efficiency of the collector evaluated by Equation (7):

$$
\eta_{\mathrm{th}}=\eta_{0} \cdot \mathrm{IAM}-\left(\mathrm{a}_{1}+\mathrm{a}_{2} \cdot \Delta \mathrm{t}\right) \cdot \frac{\Delta \mathrm{t}}{\mathrm{G}}
$$

- $\quad \eta_{0}$ is the optical efficiency;

- $\Delta t$ is the difference between average fluid temperature into collectors and average surroundings temperature [21];

- $\quad \mathrm{a}_{1}$ and $\mathrm{a}_{2}$ are the linear and quadratic heat loss coefficients given in Table 3.

The IAM values are fitted with a polynomial function reported in Equation (8), based on the data provided by the manufacturer in Table 4 . The coefficients of the polynomials obtained for all the considered cases are presented in Table 7.

$$
\mathrm{IAM}_{\text {tra;long }}=\mathrm{a} \cdot \theta^{2}+\mathrm{b} \cdot \theta+\mathrm{c}
$$

where $\theta$ is the incidence angle $\left(\theta^{\circ}\right)$, a function of the weather conditions for the three considered sites.

Table 7. Polynomial factors.

\begin{tabular}{ccccc}
\hline \multirow{2}{*}{ Parameter } & IAM $_{\text {tra }}$ & IAM $_{\text {tra }}$ & IAM $_{\text {tra }}$ & IAM $_{\text {lon }}$ \\
\cline { 2 - 5 } & FKC-2W & FT 226-2V & \multicolumn{2}{c}{ VTK 120-2 CPC } \\
\hline a & $-1.06 \mathrm{E}-04$ & $-7.62 \mathrm{E}-05$ & $1.88 \mathrm{E}-04$ & $-6.55 \mathrm{E}-05$ \\
$\mathbf{b}$ & $4.44 \mathrm{E}-03$ & $3.17 \mathrm{E}-03$ & $-9.55 \mathrm{E}-03$ & $2.70 \mathrm{E}-03$ \\
$\mathbf{c}$ & $9.54 \mathrm{E}-01$ & $9.66 \mathrm{E}-01$ & $1.10 \mathrm{E}+00$ & $9.71 \mathrm{E}-01$ \\
\hline
\end{tabular}

In the case of VTK 120-2 CPC collector, the value of IAM is estimated as the product of longitudinal and transversal IAM as in Equation (9).

$$
\mathrm{IAM}=\mathrm{IAM}_{\mathrm{tra}} \cdot \mathrm{IAM}_{\mathrm{lon}}
$$

The optical efficiency $\eta_{0}$ and thermal loss coefficients $a_{1}$ and $a_{2}$ are determined experimentally. Optical and thermal losses both have an impact on the collector efficiency, and their relative contributions depend mainly on the physical design of the collector. In Figure 4, the solar collector efficiency $\eta_{\text {col }}$, calculated according to Equation (10), at different solar radiation levels is illustrated for the three types of considered collectors. Similar values of efficiency about evacuated tube collectors are presented by Atkins [22].

$$
\eta_{\mathrm{col}}=\eta_{0}-\left(\mathrm{a}_{1}+\mathrm{a}_{2} \cdot \Delta \mathrm{t}\right) \cdot \frac{\Delta \mathrm{t}}{\mathrm{G}}
$$

Different capacities of thermal storage, expressed in hours, are considered, from 0 to $24 \mathrm{~h}$ with a $3 \mathrm{~h}$ step. The resulting storage capacities are in the range from 600 to $4830 \mathrm{kWh}$ and 980 to $7850 \mathrm{kWh}$, for mesophilic and thermophilic conditions, respectively.

The effect of the thermal energy produced by the solar section is to reduce the biogas consumption for the reactor heating. Thus, the highest the solar energy supplied to the reactor, the highest the biogas that can be sent to the upgrading section to produce biomethane, that, in turn, can be injected into the grid. This benefit is evaluated according to the amount of saved biomethane (expressed as the energy content, in MWh, of the additional biomethane annually produced with respect to the base case mesophilic/thermophilic AD, without solar system). The calculation is carried out on an hourly basis: per each hour of the year the (i) the heat available from the solar system is calculated (including heat 
stored or retrieved from the storage); (ii) the $\mathrm{AD}$ reactor heat requirement is calculated; iii) the saved biogas/biomethane is obtained as the difference between (ii) and (i).

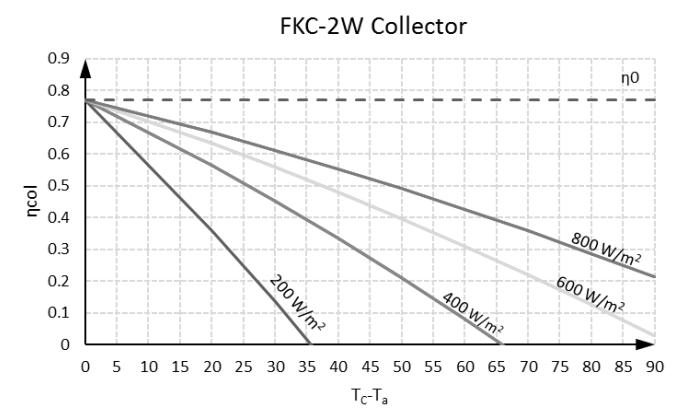

(a)

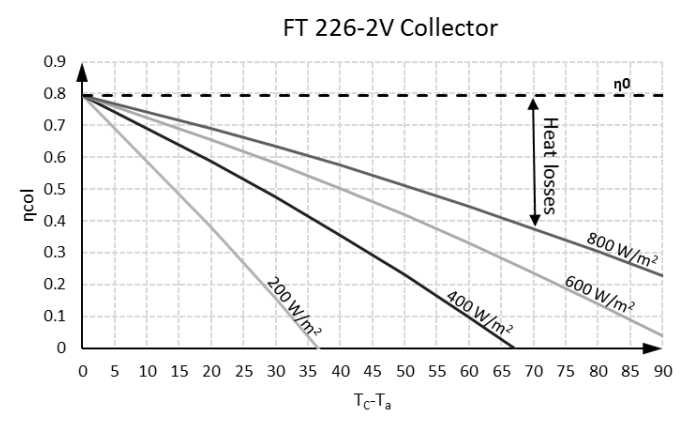

(b)

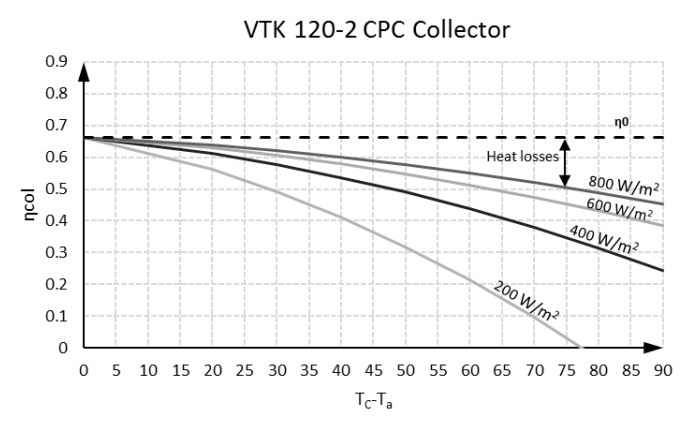

(c)

Figure 4. Efficiencies for FKC-2W collector (a), FT 226-2V collector (b) and VTK 120-2 CPC evacuated collector (c) at different solar radiation levels.

\subsection{Economic Analysis}

An increase in the saved biomethane can be obtained, obviously, with a larger solar field area. Of course, for increasing amounts of saved biomethane an increase in the additional revenues from the biomethane selling are obtained. On the other hand, for increasing solar field area, the cost related to the solar section increases as well. With this in mind, a preliminary and simplified economic analysis is carried out, with the aim of evaluating the additional investment cost for the solar section (for different area of the solar field and for the three sites) vs. the additional revenues from saved biomethane selling. The analysis is not including the investment costs for the $\mathrm{AD}$ and upgrading system as well as it is not including the revenues from the biomethane produced in the reference operating condition (i.e., mesophilic/thermophilic case without solar integration). Thus, the economic evaluation is based only on the additional costs/revenues. Even though this approach is rather simplified, it can provide some interesting clues on whether the addition of the solar section might be sustainable, without altering the $\mathrm{AD} / \mathrm{biomethane} \mathrm{profitability.} \mathrm{A} \mathrm{whole} \mathrm{life} \mathrm{cycle} \mathrm{cost} \mathrm{analysis,} \mathrm{including} \mathrm{the} \mathrm{AD} \mathrm{plant}$ investment and operation costs and overall revenues (biomethane selling and biowaste feed-in tariff), could provide a wider picture of the economic sustainability, but it is out of the scope of this work and suggested for future analysis.

The total investment cost for the solar section $\left(\mathrm{C}_{\text {inv }}\right)$ is estimated starting from the specific costs for the solar collectors and for the storage system. The specific costs of the solar collectors are presented in Table 8, according to Bosch catalogue costs 2016 [13]: these costs include the supply of the entire solar thermal kit and exclude installation. The cost of the storage tank is assumed equal to $8.20 \mathrm{Euro} / \mathrm{kWh}$ [23]. Tables S21 to S26 in Supplementary Materials report the investment costs for all the analysed solutions (mesophilic/thermophilic; storage hours), with resulting solar field area between 0 and 10,000 $\mathrm{m}^{2}$. 
Table 8. Specific costs of different solar collector types.

\begin{tabular}{cc}
\hline Collector Type & Costs $\left(\right.$ Euro/m $\left.{ }^{\mathbf{2}}\right)$ \\
\hline FKC-2W & 237.34 \\
FT 226-2V & 414.71 \\
VTK 120-2 CPC & 773.09 \\
\hline
\end{tabular}

Maintenance cost for the solar system $\left(\mathrm{C}_{\mathrm{m}}\right)$ is evaluated as $1.0 \%$ of initial investment cost [24].

For the assessment of the annual revenues ( $\left.\mathrm{B}_{\text {years }}\right)$ from the biomethane selling, the Italian Ministerial Decree dated 2 March 2018 [25] is considered. According to this decree, the injection into the grid provides a revenue equal to the natural gas price (average of the last available three months values), reduced by $5 \%$, assumed equal to 20.41 Euro/MWh [26]. Additionally, in the specific case of SS-OFMSW, for each $5 \mathrm{GCal}$ of biomethane injected into the grid, a certificate (CIC) is acknowledged, with a value of 375 Euro each, for the first 10 years (corresponding to 64.54 Euro/MWh). The Italian incentives are representative of highly advantageous subsidy, with respect to other European countries [3].

The parameter used to evaluate the investment is the simple payback time (PBT). The PBT is calculated as the ratio between the $C_{\text {inv }}$ and the net annual revenues, calculated as the difference between $B_{\text {years }}$ and $C_{m}$, as given by (11):

$$
\mathrm{PBT}=\frac{\mathrm{C}_{\mathrm{inv}}}{\left(\mathrm{B}_{\text {years }}-\mathrm{C}_{\mathrm{m}}\right)}
$$

\section{Results}

This section summarizes the main results of the analysis. The total thermal power required by the digester-made by the two contributions $Q_{\text {disp }}$ and $Q_{\text {load }}$-depends mainly on the internal temperature of the anaerobic digester (i.e., mesophilic/thermophilic) and on the external temperature, changing during the year, in the different geographical locations. The average power required to maintain the mesophilic temperature conditions in the digester varied in the range from $80-100 \mathrm{~kW}$ in summer (July) to 190-200 kW in winter (January). While, in the thermophilic condition case, it varied in the range from $210-230 \mathrm{~kW}$ in summer (July) to $310-340 \mathrm{~kW}$ in winter (January). The trend of average monthly thermal power required during the year is reported in Figure S1 of Supplementary Materials, showing that the contribution of the heat loss through the reactor surfaces is quite small. Specifically, the results indicate that up to $96.4 \%$ (mesophilic conditions) or $97.2 \%$ (thermophilic conditions) of the heat required by the digester operation is used to raise the feedstock temperature to the operating temperature, while the remaining part is utilised to keep the process temperature constant.

\subsection{Saved Biomethane}

This section reports the results in term of additional amount of biomethane (i.e., saved biomethane), not used for heating the digester. The saved biomethane is calculated as the difference between the actual amount of available biomethane in each mesophilic/thermophilic case and the amount of biomethane available in the base reference case, which is the mesophilic/thermophilic one without solar system (in the different sites).

Figure 5 reports the amount of saved biomethane by introducing in the system three different types of solar collectors, with different storage systems, in the three sites in Italy. For graphical reasons, only three levels of storage, that are 6,12 , and $18 \mathrm{~h}$, are presented. Complete results are reported in Tables S3-S20 of Supplementary Materials.

A considerable difference exists between the results of the mesophilic case and the thermophilic one, due to the different hourly production of biomethane $\left(84 \mathrm{Nm}^{3} / \mathrm{h}\right.$ and $100.8 \mathrm{Nm}^{3} / \mathrm{h}$, respectively). The areas of the solar collectors in the thermophilic conditions (Figure $5 b, d, f$ ) are significantly larger than in the mesophilic case, because the thermophilic reactor requires a larger amount of thermal energy compared to the mesophilic case. Saved biomethane reaches 700-750 MWh/year in the mesophilic 
conditions (Figure 5a,c,e) and 1300-1500 MWh/year in the thermophilic conditions (Figure 5b,d,f), for the most efficient collector (VTK 120-2 CPC) and longest storage time. However, to reach similar values in the different sites, the required area increases for sites with low annual solar irradiation.

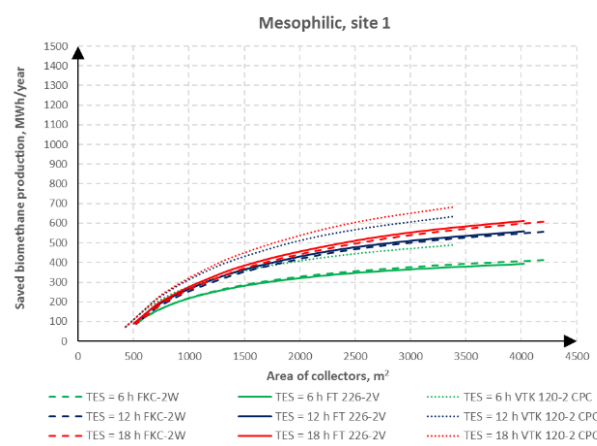

(a)

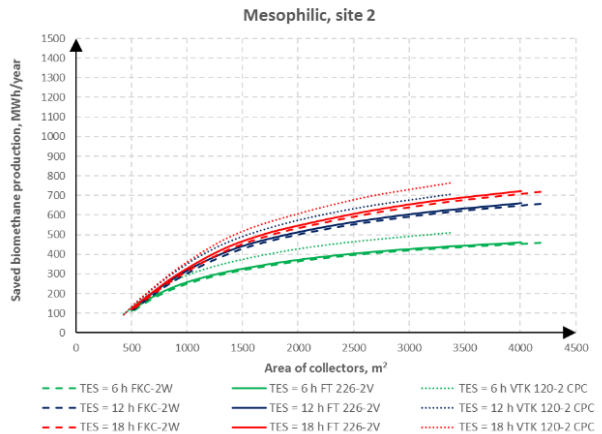

(c)

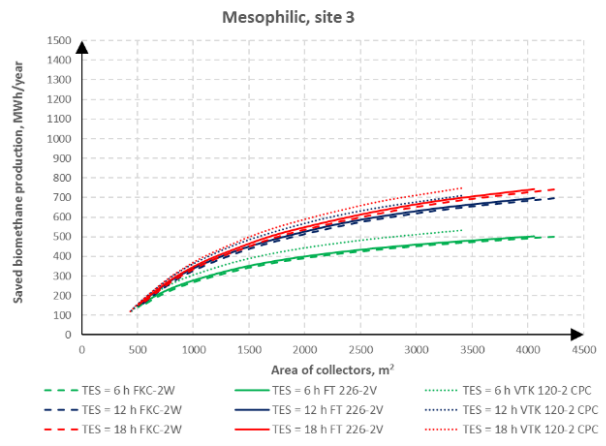

(e)

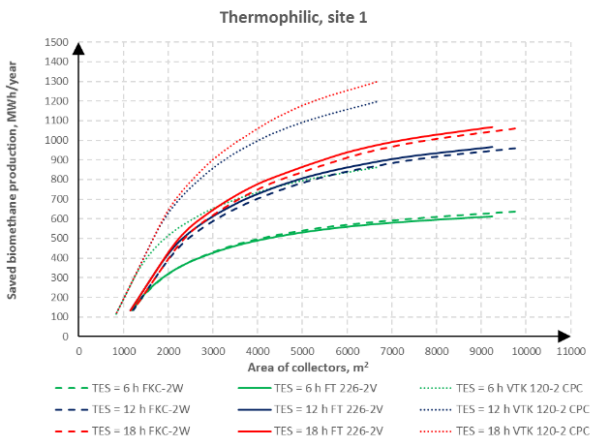

(b)

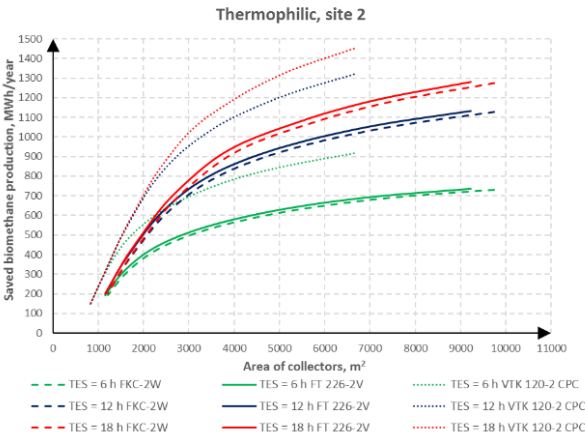

(d)

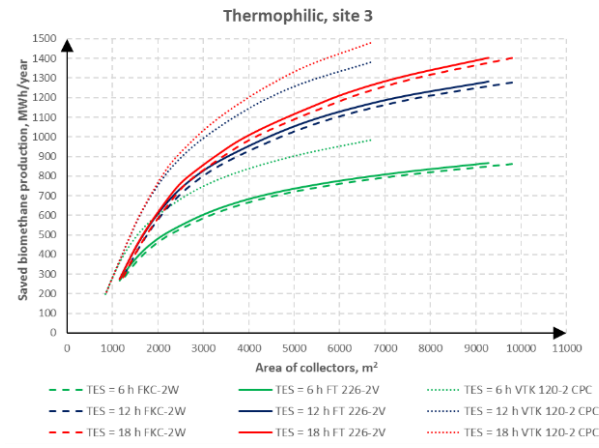

(f)

Figure 5. Annual biomethane savings as a function area of solar collectors, thermal storage size and different types of collectors: (a) Mesophilic condition site 1, (b) Thermophilic condition site 1, (c) Mesophilic condition site 2, (d) Thermophilic condition site 2, (e) Mesophilic condition site 3, (f) Thermophilic condition site 3 .

As expected, the saved biomethane fraction (ratio of annually saved biomethane to annually biogas sent to boiler in the base case without solar integration) increases with the increasing of the area of collectors, storage tank size, and with collector type. Considering a thermal storage of $18 \mathrm{~h}$ and a surface of the collectors FKC-2W of about $3300 \mathrm{~m}^{2}$ in site 1, the fractions of biomethane saved annually are equal to $38 \%$ (564 MWh/year) and $24 \%$ (655 MWh/year) for the mesophilic and thermophilic conditions, respectively. In addition, under the same conditions (site $1,18 \mathrm{~h}$ and $3300 \mathrm{~m}^{2}$ ), using the collector VTK 120-2 CPC type, the fractions of saved biomethane increase to $46 \%$ (683 MWh/year) and 35\% (959 MWh/year) for mesophilic and thermophilic conditions, respectively. The additional 
biomethane produced by the integrated system might be regarded as a way to store solar energy into an easily deliverable biofuel.

Finally, we can observe that results of saved biomethane obtained using collectors FKC-2W and FT 226-2V are quite similar, at the same storage capacity conditions, while the use of collector VTK 120-2 CPC may provide higher savings.

\subsection{Economic Results}

Figure 6 presents the results of the economic assessment in terms of PBT of the investment. The results are presented assuming the 10 years constraint, as it is the maximum period for receiving the economic incentives for biomethane. The investment costs are higher for solar collectors of larger surfaces with more hours of thermal storage. On the other hand, by increasing the solar field area and storage size, more biomethane is saved and additional economic benefits are possible.

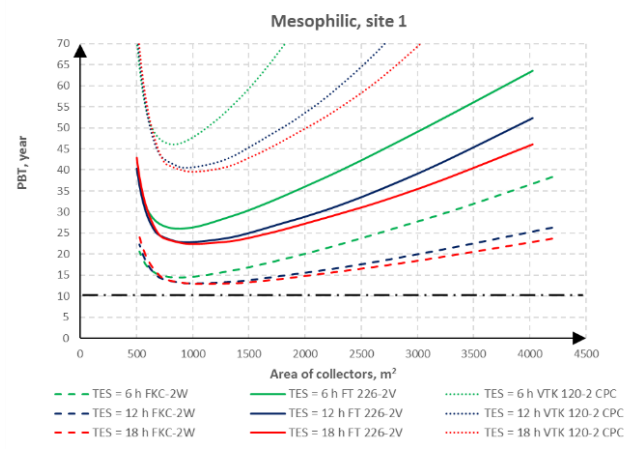

(a)

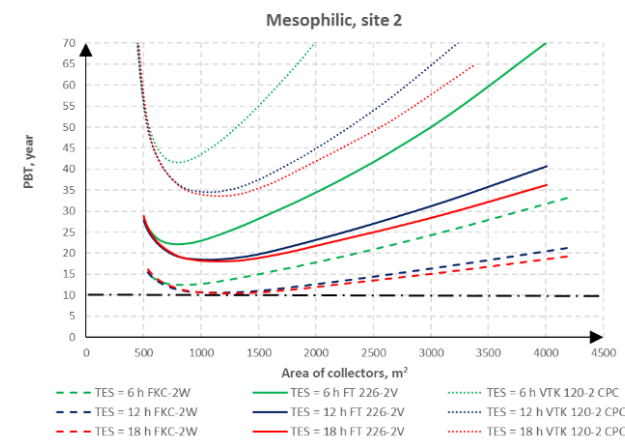

(c)

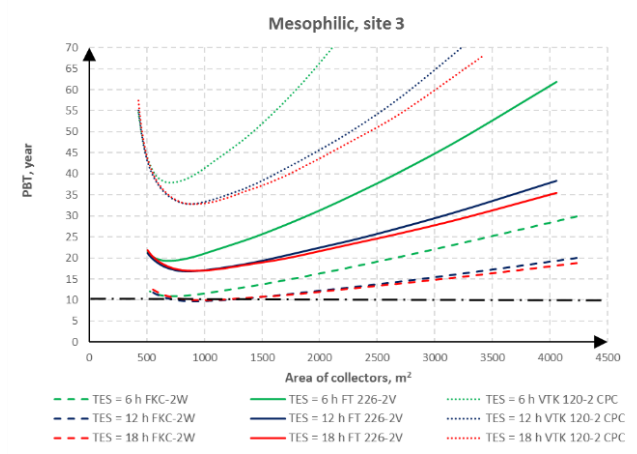

(e)

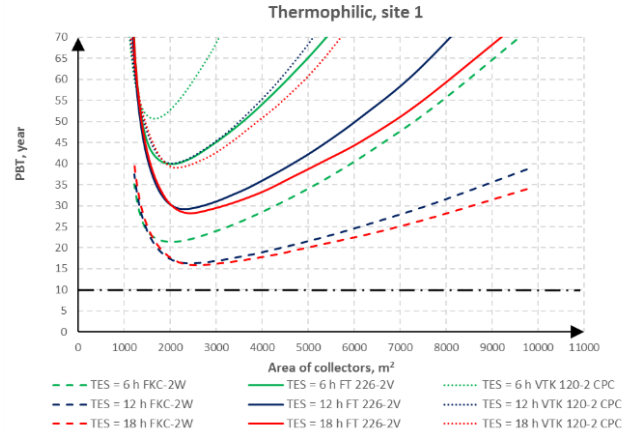

(b)

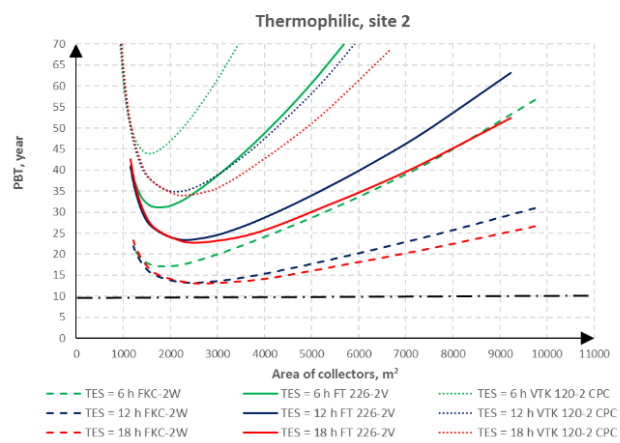

(d)

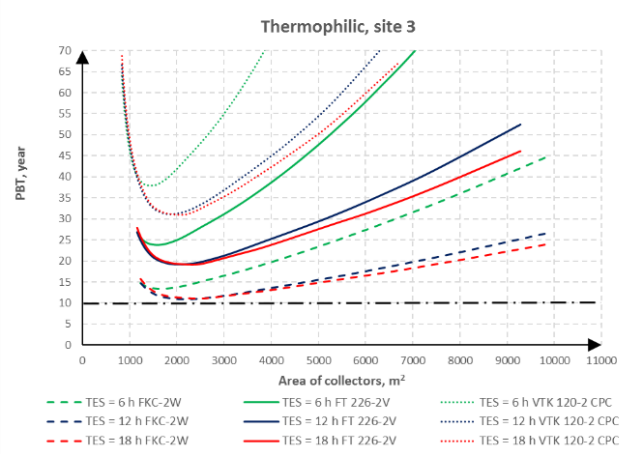

(f)

Figure 6. Payback time as a function area and types of solar collectors and thermal storage size: (a) Mesophilic condition location 1, (b) Thermophilic condition site 1, (c) Mesophilic condition site 2, (d) Thermophilic condition site 2, (e) Mesophilic condition site 3, (f) Thermophilic condition site 3. 
Figure $6 \mathrm{a}, \mathrm{c}, \mathrm{e}$ for the mesophilic conditions, show that PBT is close to 10 years for some solutions, in particular with the FKC-2W collector model, in the site 2 and 3, for a limited range of areas and capacity of storage tanks. In this case, the best solution from the economic point of view, corresponding to the minimum PBT, in Figure $6 c$,e, falls in the range between 800 and $1000 \mathrm{~m}^{2}$, with storage tank size equal to $12-18 \mathrm{~h}$.

In the thermophilic conditions, as shown in Figure $6 \mathrm{~b}, \mathrm{~d}, \mathrm{f}$ PBT is close to 10 years only in the case of site 3 for FKC-2W collector model, associated with $12-18 \mathrm{~h}$ of storage time. From Figure $6 \mathrm{f}$, it is noted that the minimum PBT falls in the range between 1900 and $2500 \mathrm{~m}^{2}$, with storage tank size equal to $12-18 \mathrm{~h}$.

It is observed that the cost of the collector with higher efficiency (VTK 120-2 CPC), which actually provides higher biomethane saving, is too high to supply economic sustainability for the studied systems.

\section{Discussion}

From these results, it is clear that the solar integration into AD producing biomethane has a limited economic sustainability and it is strongly affected by the investment cost of the solar system. Uncertainty on the investment cost plays a major role of the results, however only a reduction of such investment cost in the future may improve the economic sustainability of the system. For this reason, a sensitivity analysis is performed in order to evaluate the influence of the specific cost reduction for the different solar collector types, with respect to previously assumed values. Assuming to reduce the collector cost by 10 to $70 \%$, the PBT is recalculated, as reported in Figure 7, for two selected types of collectors, i.e., FKC-2W and VTK 120-2 CPC, in thermophilic condition with $12 \mathrm{~h}$ of thermal storage, for site 3. Table S27 in Supplementary material reports the values of the reduced specific cost of the solar collectors.

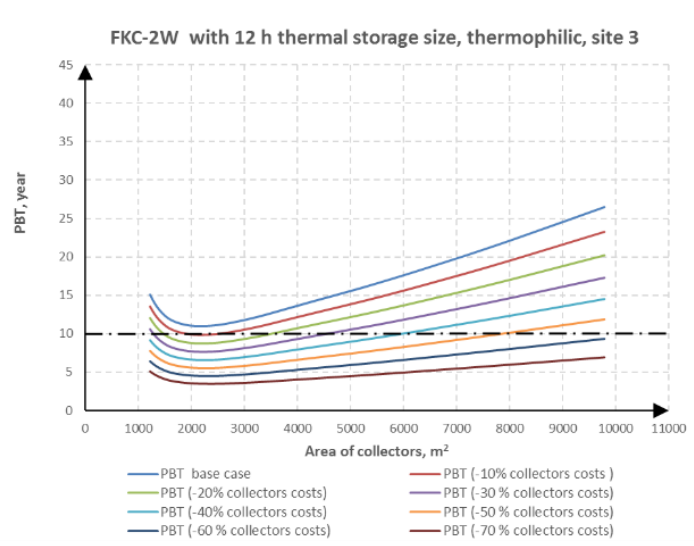

(a)

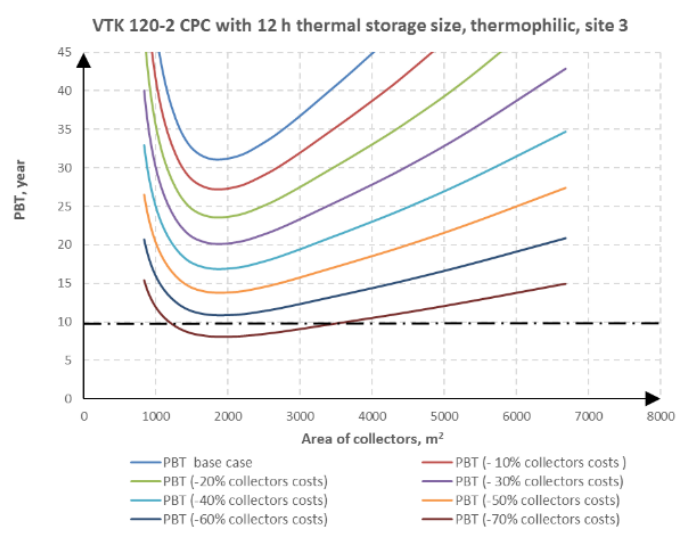

(b)

Figure 7. Payback time as a function area of solar collectors and thermal storage size, varying the specific cost of solar collectors: (a) FKC-2W with $12 \mathrm{~h}$ thermal storage thermophilic condition site 3, (b) VTK 120-2 CPC with $12 \mathrm{~h}$ thermal storage thermophilic condition site 3.

Figure 7 shows that reducing the specific cost, the PBT values obviously decrease, providing some acceptable economic solutions. In the FKC-2W collector case with $12 \mathrm{~h}$ thermal storage size, the PBT becomes in general lower than 10 years when the specific cost is below $189.87 \mathrm{Euro} / \mathrm{m}^{2}(-20 \%$ collector costs). While in the case of the VTK 120-2 CPC collector with $12 \mathrm{~h}$ thermal storage size, the PBT becomes lower than 10 years only if the specific cost is $231.93 \mathrm{Euro} / \mathrm{m}^{2}(-70 \%$ collector costs).

Finally, we recalculate the PBT for some selected cases (site 3, thermophilic case, FKC-2W and VTK 120-2 CPC collectors), considering only the income from biomethane selling at the natural gas price (without the additional incentives specific for the Italian situation) equal to 20.41 Euro/MWh (which is about $25 \%$ of the overall selling price considered in the base case). Being that the Italian incentives are 
quite advantageous, with respect to other European countries, we expect that other results, eventually calculated considering other intermediate cases of incentives, will lay within the range of our results calculated with and without the Italian incentives, providing a more general interpretation of the presented results.

Of course, the revenues obtainable by selling the biomethane at the natural gas price, without incentives, are also dependant on the trend of the natural gas market, which presented average annual values in the range 19-26 Euro/MWh in the last ten years in Italy, according to a decreasing trend [26].

Results in Figure 8 shows that the PBT calculated without incentives is always higher than 10 years, as expected, confirming that the incentives mechanism is fundamental to support the economic sustainability of solar integration in AD producing biomethane.

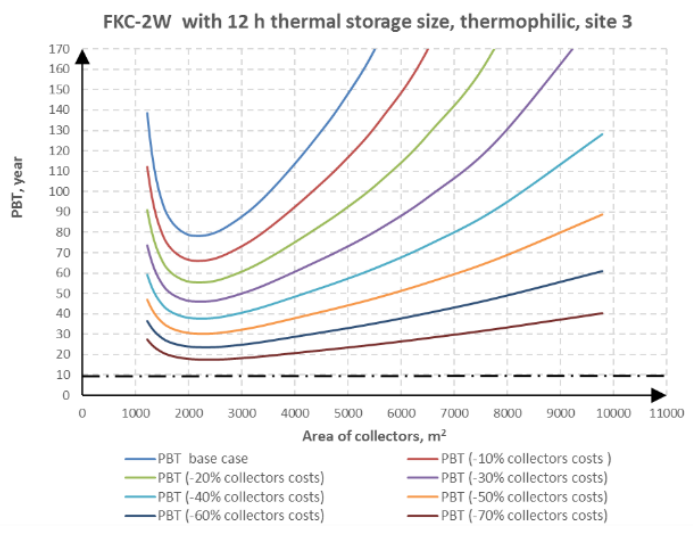

(a)

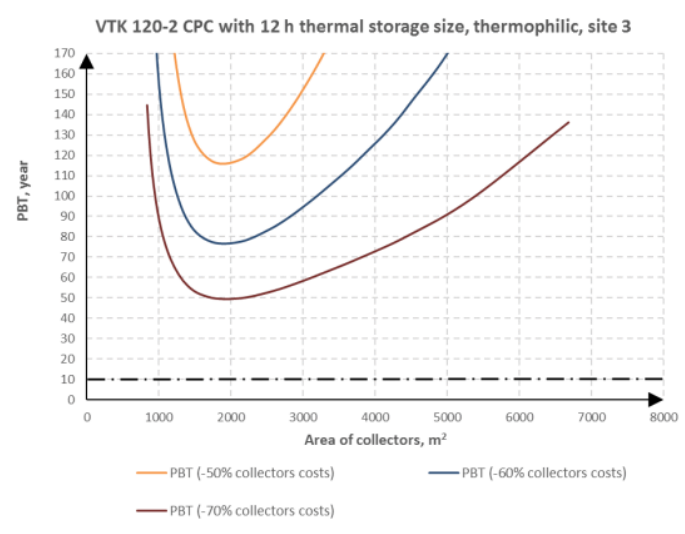

(b)

Figure 8. Payback time without incentives as a function area of solar collectors and thermal storage size, varying the specific cost of solar collectors: (a) FKC-2W Thermophilic condition site 3, (b) VTK 120-2 CPC Thermophilic condition site 3.

\section{Conclusions}

The possibility of integrating thermal solar energy into anaerobic digestion reactor, with biogas upgrading to biomethane, is studied, considering mesophilic/thermophilic conditions, three different types of solar collectors (Bosch FKC-2W, FT 226-2V, VTK 120-2 CPC), and three different Italian sites. The influence of the solar collector's area and the thermal storage size are studied.

The integration of solar source allows reducing the amount of biogas required for heating the digester, thus more biogas is sent to the upgrading section, producing more biomethane that can be sent to the grid. The saved biomethane amount depends on the different studied conditions. In general, it is larger in thermophilic case with respect to the mesophilic one; it increases with the area of the collectors, with the storage capacity, with decreasing latitude of the site and with improved collector technology.

The amount of yearly saved biomethane lays in the range 100-700 MWh/y and 100-1500 MWh/y for the mesophilic and thermophilic cases, respectively. This amount represents a fraction of the required heat for the gas boiler in the base case, ranging from $4 \%$ to $55 \%$, depending on the different considered variables.

Results of the simplified and preliminary economic analysis show that in the mesophilic conditions there are some economically acceptable solutions with PBT close to 10 years, in particular with the collector FKC-2W type for the range between 800 and $1000 \mathrm{~m}^{2}$, with storage tank size equal to $12-18 \mathrm{~h}$ in the sites 2 and 3. In the thermophilic conditions, the minimum PBT is 10 years, and it can be obtained with collector area between 1900 and $2500 \mathrm{~m}^{2}$, with storage tank capacity 12-18 h, in the site 3 .

It is observed that the economic acceptability can be reached only using the less expensive collector, even if its efficiency allows lower biomethane savings. Future reduction of solar collector costs might improve the economic feasibility. However, when the payback time is calculated excluding the Italian 
incentives, its value is always higher than 10 years. Therefore, incentives mechanism is a fundamental support to the economic sustainability of solar integration in these systems.

Further analysis, based on complete life cycle costing of the integrated $\mathrm{AD} /$ solar system, is however required to better evaluate the main economic indicators for the whole system, also considering the uncertainties associated with costs and revenues and other boundary conditions as climate change impact on solar energy.

Finally, the proposed integration can be regarded as a way to store solar energy, considering that the solar energy is the most abundant energy resource with the potential to become a major component of a sustainable global energy solution.

Supplementary Materials: The following are available online at http://www.mdpi.com/1996-1073/13/17/4292/s1.

Author Contributions: Conceptualization, L.L.; Methodology, L.L., B.M.; Formal analysis, S.F.; Investigation, L.L., B.M.; Writing- Original draft preparation, S.F.; Writing- Reviewing and Editing, L.L., B.M.; Visualization, S.F.; Supervision, L.L. All authors have read and agreed to the published version of the manuscript.

Funding: This research received no external funding.

Conflicts of Interest: The authors declare no conflict of interest.

\section{References}

1. EurObserv'ER Report. The State of Renewable Energies in Europe. 2018. Available online: https://www.isi. fraunhofer.de/content/dam/isi/dokumente/ccx/2019/The_State_of_RES_in_Europe-2018-GB.pdf (accessed on 10 July 2020).

2. Budzianowski, W.M.; Budzianowska, D.A. Economic analysis of biomethane and bioelectricity generation from biogas using different support schemes and plant configurations. Energy 2015, 88, 658-666. [CrossRef]

3. Lombardi, L.; Francini, G. Techno-economic and environmental assessment of the main biogas upgrading technologies. Renew. Energy 2020, 156, 440-458. [CrossRef]

4. EBA Statistical Report. Biogas Plants EBA Statistical Report 2018. Available online: http://european-biogas. eu/2017/12/14/eba-statistical-report-2017-published-soon/ (accessed on 10 July 2020).

5. Mazzella, D. Rapporto Rifiuti Urbani, Edizione 2019 n.d. Available online: https://www.isprambiente.gov.it/ files2019/pubblicazioni/rapporti/RapportoRifiutiUrbani_VersioneIntegralen313_2019_agg17_12_2019.pdf (accessed on 10 July 2020).

6. Mahmudul, H.M.; Rasul, M.G.; Akbar, D.; Mofijur, M. Opportunities for solar assisted biogas plant in subtropical climate in Australia: A review. Energy Procedia 2019, 160, 683-690. [CrossRef]

7. Yuan, S.; Rui, T.; Xiao Hong, Y. Research and Analysis of Solar Heating Biogas Fermentation System. Procedia Environ. Sci. 2011, 11, 1386-1391. [CrossRef]

8. Ouhammou, B.; Aggour, M.; Frimane, Â.; Bakraoui, M.; El, H.; Essamri, A. A new system design and analysis of a solar bio-digester unit 2019. Energy Convers. Manag. 2019, 198, 111779. [CrossRef]

9. Zhong, Y.; Roman, M.B.; Zhong, Y.; Archer, S.; Chen, R.; Deitz, L.; Hochhalter, D.; Balaze, K.; Sperry, M.; Werner, E.; et al. Using anaerobic digestion of organic wastes to biochemically store solar thermal energy. Energy 2015, 83, 638-646. [CrossRef]

10. Borello, D.; Evangelisti, S.; Tortora, E.; Sapienza, D.; Sapienza, C.; Sapienza, D. Modelling of a CHP SOFC System Fed with Biogas from Anaerobic Digestion of Municipal Waste Integrated with Solar Collectors and Storage Unit. Int. J. Thermodyn. 2013, 16, 28-35. [CrossRef]

11. Igoni, A.H.; Ayotamuno, M.J.; Eze, C.L.; Ogaji, S.O.T. APPLIED Designs of anaerobic digesters for producing biogas from municipal solid-waste. Appl. Energy 2008, 85, 430-438. [CrossRef]

12. Khoshnevisan, B.; Tsapekos, P.; Alvarado-Morales, M.; Rafiee, S.; Tabatabaei, M.; Angelidaki, I. Life cycle assessment of different strategies for energy and nutrient recovery from source sorted organic fraction of household waste. J. Clean Prod. 2018, 180, 360-374. [CrossRef]

13. Bosch. Solar Thermal Collecotors Catalogue. Available online: https://www.bosch-thermotechnology. $\mathrm{com} / \mathrm{it} / \mathrm{it} / \mathrm{residenziale/informazioni/documentazione/certificazioni/certificazioni-collettori-solari-termici/}$ (accessed on 10 August 2020).

14. Bosch. Bosch FKC 2 W Technical Features Bosch. Available online: https://www.bosch-thermotechnology. com/ocsmedia/optimized/full/o329626v288_6720868306.pdf (accessed on 20 February 2019). 
15. Bosch. Summary of EN 12975 Test Results, annex to Solar KEYMARK Certificate st o r sign Annual collector output based on EN 12975 Test Results, annex to Solar KEYMARK Certificate Annual collector output kWh. 2016. Available online: https://www.bosch-thermotechnology.com/it/media/country_pool/residential/ knowledge/dokumente/certificato_ft_226-2v_-_dati_tecnici.pdf (accessed on 10 May 2020).

16. Bosch. Bosch VK 120- 2 CPC EN 12975 Test Results, Certificate Licence Number Issued 011-7S2461. 2016, pp. 4-5. Available online: https://www.bosch-thermotechnology.com/it/it/ocs/residenziale/collettoresolare-a-tubi-sottovuoto-vk120-2-cpc-789933-p/ (accessed on 10 August 2020).

17. Globalsolaratlas. Global Irradiation. 2019. n.d. Available online: https://globalsolaratlas.info/download/italy (accessed on 10 August 2020).

18. Soares, T.; Silva, M.; Sousa, T.; Morais, H.; Vale, Z. Energy and Reserve under Distributed Energy Resources Management-Day-Ahead, Hour-Ahead and Real-Time. Energies 2017, 10, 1778. [CrossRef]

19. Duffie, J.A.; Beckman, W.A. Solar Engineering of Thermal Processes Solar Engineering. Energies 2013. [CrossRef]

20. Janotte, N.; Meiser, S.; Pitz-paal, R.; Fischer, S. Quasi-dynamic analysis of thermal performance of parabolic trough collectors. In Proceedings of the SolarPACES 2009 Conference Proceedings, Berlin, Germany, 15-18 September 2009.

21. Technology Cooling Q. Quality Assurance in Solar Thermal Heating and Cooling Technology-Keeping Track with Recent and Upcoming Developments. 2012. Available online: http://www.estif.org/fileadmin/estif/ content/projects/QAiST/QAiST_results/QAiST\%20D2.3\%20Guide\%20to\%20EN\%2012975.pdf (accessed on 10 August 2020).

22. Atkins, M.J.; Walmsley, M.R.W.; Morrison, A.S. Integration of solar thermal for improved energy efficiency in low-temperature-pinch industrial processes. Energy 2010, 35, 1867-1873. [CrossRef]

23. Thu-trang, N.; Viktoria, M.; Anders, M. SSCA A review on technology maturity of small scale energy storage. Renew. Energy Environ. Sustain. 2017, 2, 36. [CrossRef]

24. NERL. Distributed Generation Renewable Energy Estimate of Costs. Available online: https://www.nrel.gov/ analysis/tech-lcoe-re-cost-est.html (accessed on 10 August 2020).

25. Ministerial Decree Dated. IL Ministro Dello Sviluppo Economico. 2018; pp. 1-43. Available online: https: //www.mise.gov.it/index.php/it/normativa/decreti-interministeriali/2037836-decreto-interministeriale-2marzo-2018-promozione-dell-uso-del-biometano-nel-settore-dei-trasporti (accessed on 10 August 2020).

26. GME. Gestore Mercati Energetcici. n.d. Available online: https://www.mercatoelettrico.orgn.d (accessed on 10 August 2020).

(C) 2020 by the authors. Licensee MDPI, Basel, Switzerland. This article is an open access article distributed under the terms and conditions of the Creative Commons Attribution (CC BY) license (http://creativecommons.org/licenses/by/4.0/). 